Article

\title{
Prevalence of COVID-19 Infection among Patients with Diabetes and Their Vaccination Coverage Status in Saudi Arabia: A Cross-Sectional Analysis from a Hospital-Based Diabetes Registry
}

Ayla M. Tourkmani ${ }^{1}$, Abdulaziz Mansour Bin Rsheed ${ }^{1}$, Mohammad Saad AlEissa ${ }^{1}$, Sulaiman Mohammed Alqahtani ${ }^{1}$, Azzam Fahad AlOtaibi ${ }^{1}$, Mohammed S. Almujil ${ }^{1}$, Ibraheem H. AlKhshan ${ }^{2}$, Turki N. ALNassar ${ }^{3}$, Mansour N. ALOtaibi ${ }^{3}$ and Alian A. Alrasheedy ${ }^{4, *(D)}$

1 Chronic Illness Center, Family and Community Medicine Department, Prince Sultan Military Medical City, Riyadh 11159, Saudi Arabia; aturkmany@psmmc.med.sa (A.M.T.); ambinrasheed@psmmc.med.sa (A.M.B.R.); maleissa@psmmc.med.sa (M.S.A.); smqahtani@psmmc.med.sa (S.M.A.); af.otaibi@psmmc.med.sa (A.F.A.); malmuji@@psmmc.med.sa (M.S.A.)

2 College of Medicine, Imam Mohammad Ibn Saud Islamic University, Riyadh 13317, Saudi Arabia; ihialkhashan@sm.imamu.edu.sa

3 Health Services, Ministry of Defense, Riyadh 12426, Saudi Arabia; tnalnassar@psmmc.med.sa (T.N.A.); motaibi@msd.med.sa (M.N.A.)

check for updates

Citation: Tourkmani, A.M.; Bin Rsheed, A.M.; AlEissa, M.S.; Alqahtani, S.M.; AlOtaibi, A.F.; Almujil, M.S.; AlKhshan, I.H.; ALNassar, T.N.; ALOtaibi, M.N.; Alrasheedy, A.A. Prevalence of COVID-19 Infection among Patients with Diabetes and Their Vaccination Coverage Status in Saudi Arabia: A Cross-Sectional Analysis from a Hospital-Based Diabetes Registry. Vaccines 2022, 10, 310. https:// doi.org/10.3390/vaccines 10020310

Academic Editor: Giuseppe La Torre

Received: 30 January 2022 Accepted: 13 February 2022 Published: 16 February 2022

Publisher's Note: MDPI stays neutral with regard to jurisdictional claims in published maps and institutional affiliations.

Copyright: (C) 2022 by the authors. Licensee MDPI, Basel, Switzerland. This article is an open access article distributed under the terms and conditions of the Creative Commons Attribution (CC BY) license (https:// creativecommons.org/licenses/by/ $4.0 /)$.
4 Department of Pharmacy Practice, College of Pharmacy, Qassim University, Buraidah 51452, Saudi Arabia

* Correspondence: aarshiedy@qu.edu.sa

\begin{abstract}
Patients with diabetes have a higher risk of severe infection and mortality due to COVID-19. Considering the current limited effective pharmacological treatments, vaccination remains one of the most effective means to control the pandemic. The current study aimed to determine the prevalence of COVID-19 infection and the rate of COVID-19 vaccination coverage among patients with type 2 diabetes mellitus. The patients were identified from a diabetes hospital registry at Prince Sultan Military Medical City, Riyadh, Saudi Arabia in July 2021. The history of COVID-19 infection and the vaccination status were retrieved from the National Health Electronic Surveillance Network (HESN) program and the Seha platform, respectively. A total of 11,573 patients were included in this study (representing $99.5 \%$ of all patients in the registry). A total of 1981 patients (17.1\%) had a history of confirmed COVID-19 infection. The rate of vaccination with a 1 st dose was $84.8 \%(n=9811)$, while the rate of full vaccination with the 2 nd dose was $55.5 \%(n=6422)$. The analysis showed that a higher proportion of male patients were fully vaccinated than female patients $(61.0 \%$ versus $51.2 \%$, $p<0.001)$. There were statistically significant differences among the age groups, with the full vaccination rate ranging from $59.0 \%$ for the $61-70$-year-old age group to $49.0 \%$ for the $>80$-year-old age group $(p<0.001)$. The patients with no previous history of COVID-19 infection were more likely to get fully vaccinated than those with a previous history of the infection $(63.9 \%$ versus $14.6 \%$, respectively, $p<0.001)$. The factors associated with a higher likelihood of unvaccinated status included the female gender (adjusted odds ratio (aOR) $=1.705$ (95\% confidence interval (CI): 1.528-1.902)), elderly patients in the age group of $61-70(\mathrm{aOR}(95 \% \mathrm{CI})=1.390(1.102-1.753))$, the age group of $71-80$ $(\mathrm{aOR}(95 \% \mathrm{CI})=1.924(1.499-2.470))$ and the age group of $>80(\mathrm{aOR}(95 \% \mathrm{CI})=3.081(2.252-4.214)$, and prior history of COVID-19 infection $(\mathrm{aOR}(95 \% \mathrm{CI})=2.501(2.223-2.813))$. In conclusion, a considerable proportion of patients with type 2 diabetes had confirmed COVID-19 infection. Continued targeted efforts are needed to accelerate vaccination coverage rates among patients with diabetes in general and the particular subgroups identified in this study.
\end{abstract}

Keywords: COVID-19; diabetes; infections; vaccination; vaccines; vaccine hesitancy 


\section{Introduction}

The coronavirus disease 2019 (COVID-19) pandemic has affected all countries globally in many aspects of life since the severe acute respiratory syndrome coronavirus 2 (SARS-CoV-2) was identified in December 2019 and the subsequent global spread of this highly contagious virus [1-3]. Many countries suffered from several waves of COVID-19 with additional stress, pressure and strain on healthcare systems [4-7]. The basic reproduction number $\left(\mathrm{R}_{0}\right)$ for COVID-19 was estimated to be in the range of 1.4 to $2.5,[2,8-10$ ] with some studies reporting higher $\mathrm{R}_{0}$ (e.g., $>6$ ) during outbreaks in some areas or regions of the world $[11,12]$. This variability in the $\mathrm{R}_{0}$ estimates is due to several factors, including the model used for its estimation, public health interventions to control the pandemic, level of implementation of precautionary measures (e.g., travel restrictions, social distancing), and population size/density [12-14]. The case fatality rate (CFR) for COVID-19 ranges from $0.87 \%$ to $2.79 \%$ in different countries, with a global CFR estimate of approximately $2.07 \%$ [2,15]. Moreover, the morbidity and mortality rate of COVID-19 is higher among individuals with comorbid conditions and among older individuals [16-20]. As of 4 November 2021, the World Health Organization (WHO) has reported more than 247 million COVID-19 cases and more than 5.02 million deaths due to COVID-19 globally [21]. In Saudi Arabia, as of 4 November 2021, there were more than 0.5 million confirmed COVID-19 cases, resulting in 8799 deaths [22]. Similar to other countries, the Ministry of Health (MoH) in Saudi Arabia was actively engaged in their efforts to mitigate the COVID-19 pandemic by formulating public health interventions and society-level preventive measures and ensuring compliance with these preventive measures in collaboration with other authorities in Saudi Arabia [23-27]. Consequently, due to the effective strategies adopted in Saudi Arabia, the $\mathrm{R}_{0}$ decreased substantially [28].

Diabetes mellitus is a chronic condition resulting in high blood glucose levels either because of the failure of insulin secretion or action [29,30]. Globally, approximately 463 million individuals suffer from diabetes, and this figure is estimated to reach 700 million by 2045 [31]. Poor glycemic control among patients with diabetes increases their chances of getting infections; therefore, these individuals need to be more cautious than the general population [32-34]. Diabetes increases the severity and mortality rate of COVID-19 [35-39]. In a study conducted in Saudi Arabia, it was found that there is a higher prevalence of diabetes among admitted COVID-19 patients [40]. Additionally, it was also confirmed that patients with diabetes have higher mortality rate due to COVID-19 than nondiabetic patients [40]. Therefore, for patients with diabetes, compliance with preventive guidelines related to COVID-19 becomes even more important [41,42].

Considering that effective pharmacological treatment to combat COVID-19 is still emerging, vaccination has become an important pillar for controlling the COVID-19 pandemic [43-45]. As different types of vaccines have shown positive results and are now available for clinical use [3,46-50], it is quite important for patients with diabetes to receive vaccinations to avoid serious debilitating COVID-19 infection [51-53]. Pfizer-BioNtech was the first COVID-19 vaccine approved by the Saudi Food and Drug Authority (SFDA) on 10 December 2020 and was subsequently introduced in Saudi Arabia [54]. This was followed by the approval and introduction of the Oxford-AstraZeneca vaccine in Saudi Arabia on 18 February 2021 [55] and the Moderna vaccine on 11 July 2021 [56]. Consequently, three vaccines are currently available in Saudi Arabia, and more efforts are made to encourage vaccination of all eligible persons as soon as possible $[57,58]$. The national vaccination program for COVID-19 was launched on 17 December 2020 [59]. It consisted of three main stages with higher priority that were initially given to the most vulnerable groups of the population $[60,61]$. The 1st stage included target groups with higher priority, such as persons aged $>65$ years old, professionals at higher risk of exposure to COVID-19 infection, obesity (BMI > 40), persons with immunodeficiency diseases or taking immunosuppressive medications, and patients with two or more chronic diseases (e.g., diabetes, hypertension, chronic kidney diseases, chronic heart disease). The second stage started on 18 February 2021 and included targeted groups such as persons $>50$ years old, patients 
with any chronic disease, and obese individuals (BMI $\geq 30$ ). The third stage included all persons interested in getting vaccinated [60-62]. The Ministry of Health emphasized that vaccines are free to all persons, including illegal residents. The vaccines were provided via a large number of centers and healthcare institutions in more than 587 centers throughout Saudi Arabia [59,61,63]. The access to vaccination centers and appointments for obtaining vaccines were made easier by e-booking services via Sehaty and Tawakkalna applications or by visiting any center of COVID-19 vaccines or health centers with vaccination services even without prior appointments, especially for elderly individuals and patients with comorbidities $[59,61,63]$. The timeline of the vaccination program is illustrated in Table 1.

Vaccine hesitancy, or the belief in conspiracy theories related to COVID-19 and misinformation about the COVID-19 pandemic and vaccines on social media have been important factors that impede COVID-19 preventive efforts, including timely vaccination coverage $[64,65]$. Other reasons for COVID-19 vaccine hesitancy include individuals' concerns about the adverse effects of COVID-19 vaccines, lack of trust in COVID-19 vaccines, planning to wait and see if the vaccines are safe, believing that COVID-19 is not a serious disease, believing that there is no need for the vaccines or being not sure about their effectiveness [66,67]. Therefore, it is important for governments to work on educating the population against these conspiracy theories, as such theories could jeopardize the strategies to mitigate the spread of COVID-19 and prevent timely and wide vaccination coverage of the populations [64,68,69]. As of 17 September 2021, it was estimated that approximately $50 \%$ of the general population in Saudi Arabia was fully vaccinated against COVID-19 [70]. Studies have also been performed to identify the predictors of COVID-19 vaccination in Saudi Arabia [71-73]. These studies can be helpful in formulating an intervention to educate the public and reduce misconceptions and accelerate the vaccination coverage of the population [73]. Although it is helpful that the population-level vaccination coverage is estimated, the percentage of the individuals or groups of patients vulnerable to COVID-19 infections and its serious complications, such as patients with diabetes, are still not known. This is particularly important, as it is evident in the literature that some patients with diabetes in Saudi Arabia had received misinformation and developed irrational fears about COVID-19 vaccination [72]. A survey-based study conducted during March-May 2021 showed that only $34.7 \%$ of the study participants with diabetes had taken the COVID-19 vaccination [72]. Consequently, the aims of this study were to determine the prevalence of COVID-19 infection among patients with type 2 diabetes mellitus and to determine the rate of COVID-19 vaccination coverage among these patients using a large hospital-based diabetes registry of more than 11,500 patients with diabetes with a history of infection and vaccination status retrieved from unified national databases/platforms. Consequently, the findings of this study could provide useful data for health policy-makers and healthcare professionals to ensure timely vaccination coverage of vulnerable patients with chronic diseases and take the relevant interventions.

Table 1. Timeline and milestones of the national COVID-19 vaccination program in Saudi Arabia.

\begin{tabular}{llccc}
\hline No. & \multicolumn{1}{c}{ Milestone } & Date & Reference \\
\hline 1 & Launching the national COVID1-19 vaccination program (1st stage) & 17 December 2020 & [59] \\
\hline 2 & Announcement of the 2nd stage of the program & 18 February 2021 & [62] \\
\hline 3 & Announcement of the administration of 2nd dose for $\geq 60$ & 28 May 2021 & [74] \\
\hline 4 & Announcement of the administration of 2nd dose for $\geq 50$ & 24 June 2021 & [75] \\
\hline 5 & Approval of mixing vaccines in Saudi Arabia & 23 June 2021 & [76] \\
\hline 6 & Approval of Pfizer/BioNTech vaccine for ages 12-18 & 27 June 2021 & [77] \\
\hline 7 & Announcement of the administration of 2nd dose for $\geq 40$ & 5 July 2021 & [78] \\
\hline
\end{tabular}


Table 1. Cont.

\begin{tabular}{clccc}
\hline No. & \multicolumn{1}{c}{ Milestone } & Date & Reference \\
\hline 8 & Announcement of the administration of 2nd dose for all eligible persons of all ages & 11 July 2021 & [79] \\
\hline 9 & $\begin{array}{l}\text { Approval of receiving the vaccine after 10 days from recovery of COVID-19 } \\
\text { infection (two doses regardless of the prior infection) }\end{array}$ & 29 July 2021 & [80] \\
\hline 10 & Approval of Pfizer/BioNTech vaccine for the ages 5-11 & 3 November 2021 & [81] \\
\hline
\end{tabular}

\section{Patients and Methods}

\subsection{Study Design, Setting and Population}

This was a cross-sectional study conducted on patients with type 2 diabetes mellitus. The patients with diabetes were identified and retrieved from the hospital diabetes registry at the Family and Community Medicine Department at Prince Sultan Military Medical City (PSMMC), Riyadh, Saudi Arabia. This registry included all patients with diabetes registered in the four chronic illness clinics at the PSMMC. The clinics are located in the middle, north, east and south regions of Riyadh city. The history of COVID-19 infection and vaccination coverage status were retrieved from the Saudi MOH platforms.

\subsection{Sample Size and Method}

The study employed a universal sampling method in which all patients in the PSMMC diabetes registry were targeted in this study. All patients with a national identification (ID) number in the registry were included. Consequently, patients with missing information in the registry, particularly the national ID number, were excluded. This is because the search in the Saudi $\mathrm{MOH}$ platforms (i.e., HESN and Seha) is only possible using the national ID number. As of 16 July 2021, there were over 11,500 patients with type 2 diabetes in the diabetes registry.

\subsection{Data Sources and Collection Procedure}

There were three data sources used in this study, namely, the PSMMC diabetes registry, Health Electronic Surveillance Network (HESN) and national vaccination record via the Seha platform. The data were collected from these three sources by trained specialized employees at PSMMC with authorized access to the databases and platforms. The data collection was performed over two weeks and was concluded on 16 July 2021. A brief description of the data sources and the procedure is summarized below.

\subsubsection{The PSMMC Diabetes Registry}

All patients with type 2 diabetes had two key identification numbers, i.e., patient number and national ID number in the diabetes registry at PSMMC. The PSMMC diabetes registry was established in February 2019 to strengthen diabetes surveillance, manage patients with diabetes, and provide a support system for clinicians to make evidence-based decisions. These registry data can also be used to see the trends in the demographic and clinical characteristics as well as the outcomes of patients with diabetes over time. Initially, in February 2019, the diabetes registry used the data from only one chronic illnesses clinic and then expanded to include the data of other chronic illness clinics affiliated with family and community medicine at PSMMC in the Riyadh region. The PSMMC diabetes registry is fully electronic, using a web-based (Oracle) system. Consequently, from the registry, the patients with diabetes were identified and retrieved, including their national ID numbers, age, and sex.

\subsubsection{Health-Diseases Surveillance Network System (HESN)}

Using the national ID number of the patients, the history of COVID-19 infection was retrieved from HESN. HESN is an official program established by the Saudi Ministry of Health. It is a Public Health-Diseases Surveillance and Management Solution (PH-DSMS) that acts as a one-stop platform that encompasses all public health information, including 
history of COVID-19 infections reported by all healthcare institutions in Saudi Arabia from the public and private sectors. To determine the history of infection with COVID-19, first, the national ID of the patients was extracted to an Excel sheet to enable the search in HESN to confirm whether the patients had COVID-19 infection, including relevant information such as the date of COVID-19 infection.

\subsubsection{National Vaccination Record via Seha Platform}

To determine the vaccination status for each patient, the data were retrieved from the national vaccination record at $\mathrm{MOH}$ in Saudi Arabia via the Seha platform. Then, the relevant data, including vaccination status, number of doses administered (i.e., 1st dose, 2nd dose) and type of vaccination were recorded.

\subsection{Data Management and Analysis}

The data were initially entered into Microsoft Excel and then transferred to SPSS for Windows version 22. Descriptive statistics (e.g., frequencies and percentages) were used to summarize the data. Inferential statistics, including the Chi-squared test and logistic regression, were used to examine the associations between the variables. The statistical significance was set at a $p$ value of $<0.05$.

\section{Results}

\subsection{Sociodemographic Characteristics}

A total of 11,573 patients with type 2 diabetes with complete identification data in the hospital-based diabetes registry were included in this study (60 patients were excluded because their relevant information could not be tracked due to missing information on their National ID number in the registry). Consequently, $99.5 \%$ of patients in the registry were included in the study. In terms of sex, $56.2 \%(n=6506)$ were female, while $43.8 \%(n=5067)$ were male. The mean age (standard deviation) of the patients was $57.71(12.07)$, and the median (interquartile range) was 58 (50-65).

\subsection{Prevalence of COVID-19 Infection among Patients with Type 2 Diabetes}

Based on the data in the HESN, 17.1\% $(n=1981)$ were infected with COVID-19. The rest of the patients showed no history of COVID-19 infection $(82.9 \% ; n=9592)$. Furthermore, among patients with no history of infection with COVID-19, 31.1\% $(n=3601)$ performed a test for COVID-19 (i.e., swab), and the results were negative, while 51.8\% $(n=5991)$ had no history of infection or underwent tests for suspected COVID-19 infection.

\subsection{Rate of Vaccination among Patients with Type 2 Diabetes Mellitus}

The overall rate of vaccination with the 1st dose among patients with type 2 diabetes was $84.8 \%(n=9811)$, while the rate of vaccination with the 2 nd dose (i.e., fully vaccinated) was $55.5 \%(n=6422)$. Consequently, in this study, $15.2 \%$ of the patients $(n=1762)$ were not vaccinated, and $44.5 \%(n=5151)$ were not fully vaccinated (Figure 1$)$. The types of vaccines administered to the patients were the Pfizer-BioNTech vaccine $(64.9 \% ; n=7510)$ and Oxford/AstraZeneca vaccine $(19.9 \% ; n=2301)$. 


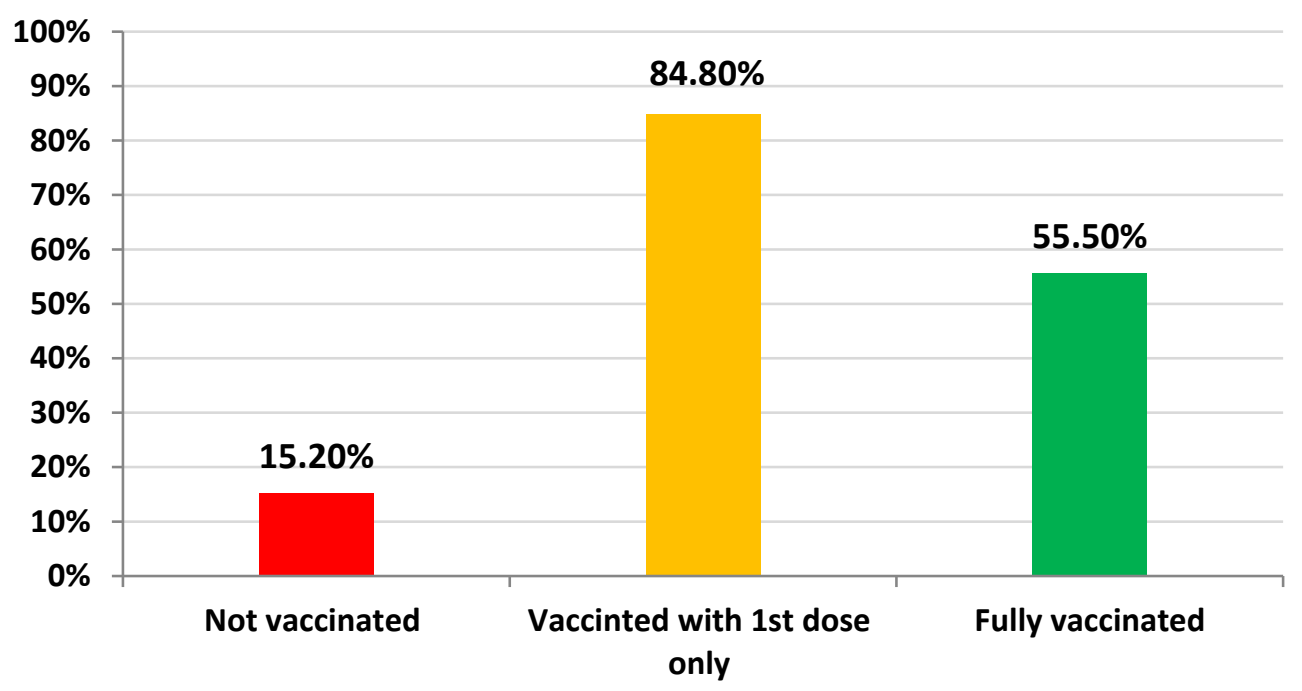

Figure 1. The rate of vaccination among patients with type 2 diabetes as of 16 July 2021.

\subsection{Association between Infection with COVID-19 and the Patients'} Sociodemographic Characteristics

There were no statistically significant associations between the infection rate and the patients' age or sex $(p<0.05)$, as shown in Table 2 . However, although not statistically significant, the elderly patients $>80$ years old were at a higher risk of infection (i.e., 19.6\%).

Table 2. Association between infection with COVID-19 and the patients' characteristics.

\begin{tabular}{|c|c|c|c|}
\hline \multirow[b]{2}{*}{ Variable } & \multicolumn{2}{|c|}{ History of COVID-19 Infection } & \multirow[t]{2}{*}{$p$ Value } \\
\hline & $\begin{array}{c}\text { Yes }(n=1981) \\
\%(n)\end{array}$ & $\begin{array}{c}\text { No }(n=9592) \\
\%(n)\end{array}$ & \\
\hline \multicolumn{3}{|l|}{ Gender } & \multirow{3}{*}{0.817} \\
\hline Male & $17.2 \%(872)$ & $82.8 \%(4195)$ & \\
\hline Female & $17.0 \%(1109)$ & $83.0 \%(5397)$ & \\
\hline \multicolumn{3}{|l|}{ Age } & \multirow{7}{*}{0.098} \\
\hline$\leq 40$ & $18.6 \%(168)$ & $81.4 \%(734)$ & \\
\hline $41-50$ & $15.5 \%(340)$ & $84.5 \%(1850)$ & \\
\hline $51-60$ & $16.8 \%(651)$ & $83.2 \%(3231)$ & \\
\hline $61-70$ & $18.1 \%(528)$ & $81.9 \%(2389)$ & \\
\hline $71-80$ & $16.9 \%(224)$ & $83.1 \%(1101)$ & \\
\hline$>80$ & $19.6 \%(70)$ & $80.4 \%(287)$ & \\
\hline
\end{tabular}

3.5. Association between Vaccination Status, the Patients' Sociodemographic Characteristics and Previous Infection

The association between vaccination status (with at least the 1st dose of the vaccine) and the characteristics of the patients in terms of sex, age, and history of previous infection were examined. As shown in Table 3, there was a statistically significant association between the vaccination status and the sex of the patients. In particular, a higher proportion of male patients was vaccinated than female patients $(88.5 \%$ versus $81.9 \%, p<0.001)$. In terms of age, the higher the age of the patients, the less likely they were to be vaccinated, with a vaccination rate ranging from $88.7 \%$ for the age group $\leq 40$ to $70.9 \%$ for the age group $>80$ $(p<0.001)$. In this study, patients with no previous history of COVID-19 infection were more likely to get vaccinated than those with a previous history of the infection $(87.1 \%$ versus $73.3 \%$, respectively, $p<0.001)$. 
Table 3. Association between vaccination status and patient characteristics.

\begin{tabular}{|c|c|c|c|}
\hline \multirow[b]{2}{*}{ Variable } & \multicolumn{2}{|c|}{ Vaccination Status (1st Dose Only) } & \multirow[t]{2}{*}{$p$ Value } \\
\hline & $\begin{array}{c}\text { Yes }(n=9811) \\
\%(n)\end{array}$ & $\begin{array}{c}\text { No }(n=1762) \\
\%(n)\end{array}$ & \\
\hline \multicolumn{3}{|l|}{ Gender } & \multirow{3}{*}{$<0.001$} \\
\hline Male & $88.5 \%(4482)$ & $11.5 \%(585)$ & \\
\hline Female & $81.9 \%(5329)$ & $18.1 \%(1177)$ & \\
\hline \multicolumn{3}{|l|}{ Age } & \multirow{7}{*}{$<0.001$} \\
\hline$\leq 40$ & $88.7 \%(800)$ & $11.3 \%(102)$ & \\
\hline $41-50$ & $88.1 \%(1929)$ & $11.9 \%(261)$ & \\
\hline $51-60$ & $86.0 \%(3338)$ & $14.0 \%(544)$ & \\
\hline $61-70$ & $83.6 \%(2438)$ & $16.4 \%(479)$ & \\
\hline $71-80$ & $79.5 \%(1053)$ & $20.5 \%(272)$ & \\
\hline$>80$ & $70.9 \%(253)$ & $29.1 \%(104)$ & \\
\hline \multicolumn{3}{|c|}{ History of previous infection with COVID-19 } & \multirow{3}{*}{$<0.001$} \\
\hline Yes & $73.3 \%(1452)$ & $26.7 \%(529)$ & \\
\hline No & $87.1 \%(8359)$ & $12.9 \%(1233)$ & \\
\hline
\end{tabular}

3.6. Association between Full Vaccination Status, the Patients' Sociodemographic Characteristics and Previous Infection

In this section, we examined the association between the full vaccination status (i.e., completed the two doses of the vaccine) and the characteristics of the patients in terms of sex, age, and history of previous infection. As shown in Table 4, there was a statistically significant association between the full vaccination status and the sex of the patients. In particular, a higher proportion of male patients were fully vaccinated than female patients $(61.0 \%$ versus $51.2 \%, p<0.001)$. In terms of age, there were statistically significant differences among the age groups. The full vaccination rate ranged from $59.0 \%$ for the 61-70-year-old age group compared to only $49.0 \%$ for the $>80$-year-old age group $(p<0.001)$. In this study, patients with no previous history of COVID-19 infection were more likely to get fully vaccinated than those with a previous history of the infection $(63.9 \%$ versus $14.6 \%$, respectively, $p<0.001$ ). The rates of full and partial vaccination coverage among the different subgroups of patients are presented in Figure 2.

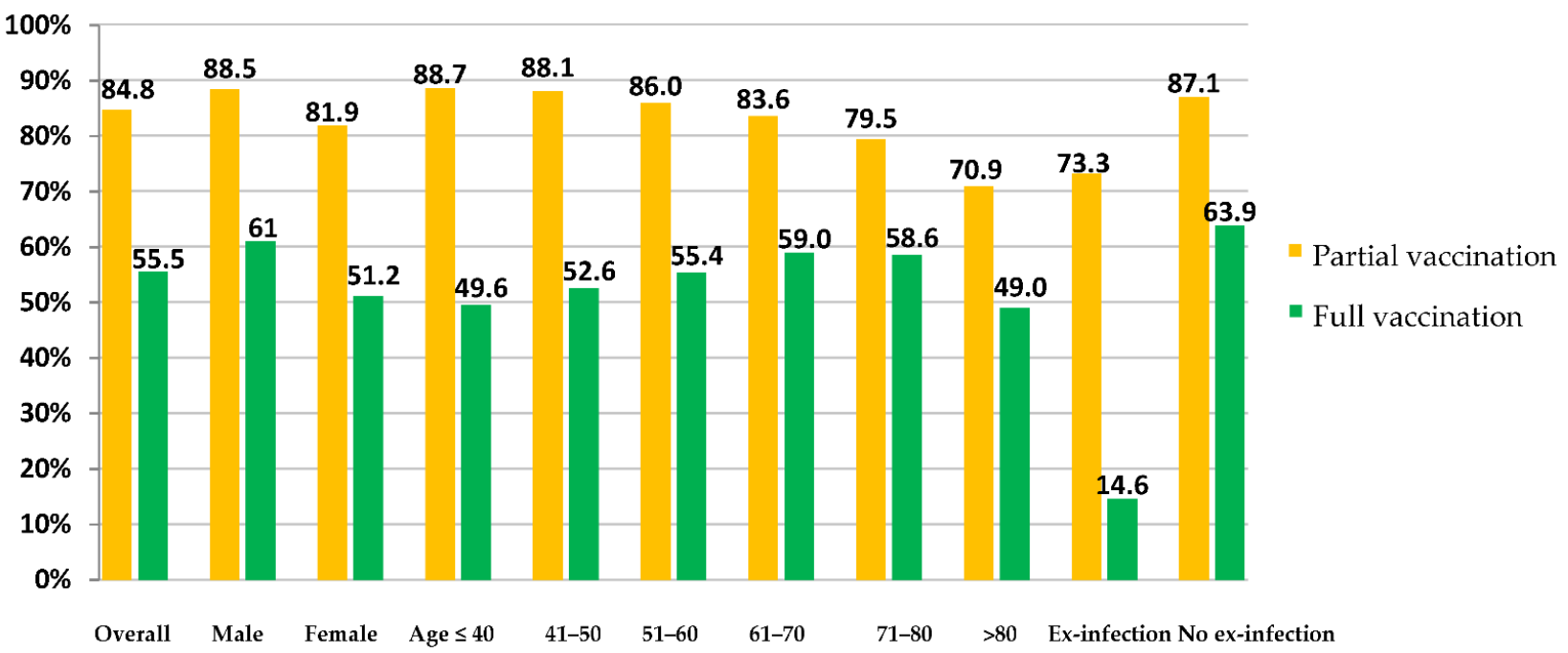

Figure 2. The rates of partial and full vaccination status among patients with type 2 diabetes as of 16 July 2021. 
Table 4. Association between full vaccination status and patient characteristics.

\begin{tabular}{|c|c|c|c|}
\hline \multirow[b]{2}{*}{ Variable } & \multicolumn{2}{|c|}{ Fully Vaccination Status (Completed Two Doses) } & \multirow[t]{2}{*}{$p$ Value } \\
\hline & $\begin{array}{c}\text { Yes }(n=6422) \\
\%(n)\end{array}$ & $\begin{array}{c}\text { No }(n=5151) \\
\%(n)\end{array}$ & \\
\hline \multicolumn{3}{|l|}{ Gender } & \multirow{3}{*}{$<0.001$} \\
\hline Male & $61.0 \%(3091)$ & $39.0 \%(1976)$ & \\
\hline Female & $51.2 \%(3331)$ & $48.8 \%(3175)$ & \\
\hline \multicolumn{3}{|l|}{ Age } & \multirow{7}{*}{$<0.001$} \\
\hline$\leq 40$ & $49.6 \%(447)$ & $50.4 \%(455)$ & \\
\hline $41-50$ & $52.6 \%(1153)$ & $47.4 \%(1037)$ & \\
\hline $51-60$ & $55.4 \%(2150)$ & $44.6 \%(1732)$ & \\
\hline $61-70$ & $59.0 \%(1721)$ & $41.0 \%(1196)$ & \\
\hline $71-80$ & $58.6 \%(776)$ & $41.4 \%(549)$ & \\
\hline$>80$ & $49.0 \%(175)$ & $51.0 \%(182)$ & \\
\hline \multicolumn{3}{|c|}{ History of previous infection with COVID-19 } & \multirow{3}{*}{$<0.001$} \\
\hline Yes & $14.6 \%(290)$ & $85.4 \%(1691)$ & \\
\hline No & $63.9 \%(6132)$ & $36.1 \%(3460)$ & \\
\hline
\end{tabular}

3.7. Logistic Regression Analysis for the Impact of Factors Associated with the Unvaccinated Status

As shown in Table 5, the logistic regression was conducted to further assess the impact of the sociodemographic characteristics on the status of being unvaccinated among the patients with type 2 diabetes mellitus, as there were 1762 patients who did not receive any vaccination for COVID-19. The findings confirmed the univariate analysis and have shown the subgroups with a higher likelihood of being unvaccinated. These included the female sex (adjusted odds ratio $(\mathrm{aOR})=1.705$ (95\% confidence interval (CI): 1.528-1.902)), elderly patients in the age group of $61-70(\mathrm{aOR}(95 \% \mathrm{CI})=1.390(1.102-1.753))$, the age group of $71-80(\mathrm{aOR}(95 \% \mathrm{CI})=1.924(1.499-2.470))$, and the age group of $>80(\mathrm{aOR}(95 \% \mathrm{CI})=3.081$ (2.252-4.214). In addition, prior history of COVID-19 infection (aOR $(95 \% \mathrm{CI})=2.501$ (2.223-2.813)) was statistically associated with being unvaccinated compared to those patients with no prior history of COVID-19 infection in the regression analysis.

Table 5. Binary logistic regression for factors associated with unvaccinated status of the patients.

\begin{tabular}{cccc}
\hline & Variable & Adjusted Odds Ratio (95\% CI) & $p$ Value \\
\hline Gender & & 1 & $p<0.001$ \\
\hline Male & $1.705(1.528-1.902)$ & $p<0.001$ \\
\hline Female & \multicolumn{1}{c}{1} & 0.786 \\
\hline Age & $1.035(0.808-1.324)$ & 0.219 \\
\hline $51-50$ & $1.155(0.918-1.453)$ & 0.006 \\
\hline $61-70$ & $1.390(1.102-1.753)$ & $p<0.001$ \\
\hline $71-80$ & $1.924(1.499-2.470)$ & $p<0.001$ \\
\hline History of previous infection with COVID-19 & $3.081(2.252-4.214)$ & $p<0.001$
\end{tabular}

$\overline{\mathrm{CI}}=$ Confidence interval. 


\section{Discussion}

This is one of the few studies that reported the actual status of vaccination against COVID-19 among patients with diabetes and the actual rate of COVID-19 infection among this vulnerable group of patients. The previous studies in the literature were focused on determining the intentions of the general public, healthcare professionals or patients to get vaccinated (i.e., examining willingness, intentions of acceptance, hesitancy, etc. [82-94], with very few studies that assessed the vaccination status of particular groups of patients (e.g., cancer patients) [95].

The overall rate of confirmed COVID-19 infection was $17.1 \%$ in type 2 diabetes patients in this study. Moreover, it was alarming that elderly patients, especially patients aged $>80$ years old, had a higher prevalence of COVID-19 infections than other patient age groups (19.6\% became infected with COVID-19). This is a considerable proportion of this group of patients given the higher risk of severe infections with COVID-19 and its related complications in type 2 diabetes patients, including the risk of hospital admission, intensive care unit admission, morbidity and mortality [96-98]. Consequently, more education and awareness activities are needed to target patients with diabetes to help reduce the incidence of COVID-19 infections and subsequently the burden on the healthcare systems to manage its complications. This is because the relationship of COVID-19 and diabetes is bidirectional, as diabetes increases the severity of the infection, while COVID-19 could cause direct damage to the pancreas and worsen hyperglycemia or could even induce the onset of diabetes in previously nondiabetic individuals [97].

The rate of fully vaccinated patients with diabetes was only $55.5 \%$, leaving a substantial number of individuals who were either not vaccinated or only partially vaccinated. This is less than expected and not consistent with the current COVID-19 vaccination program roll-out plan that was started in mid-December 2020 that aimed to ensure that almost all patients with comorbidities, including diabetes, be fully vaccinated by the time this study was conducted $[59,61]$. This is a lower-than-expected rate of vaccination coverage given that elderly patients and patients with chronic diseases, including diabetes, were given priorities to get vaccinated since the start of the program $[59,61,62,74]$. Vaccinations were available in more than 587 centers throughout Saudi Arabia. Moreover, vaccines are provided free to all patients and individuals and can be booked immediately through e-booking services via Sehaty and Tawakkalna applications or by just visiting any center of COVID-19 vaccines or health centers with vaccination services even without prior appointment, especially for elderly individuals and patients with comorbidities [63]. Consequently, based on the wide availability of vaccines, the large number of centers for vaccinations, all of which are free for all eligible individuals and are easily accessible through electronic booking and in-person appointments, including the priority given to the elderly and patients with diabetes, it is expected that the vast majority of elderly and patients with diabetes patients are fully vaccinated at the time of the study (Table 1). In fact, the COVID-19 vaccination program at the time of the study was at an advanced stage, as it reached the stage of vaccination of children in the age group of 12-18 years old in early July 2021 [77]. Lower vaccination coverage can be attributed to vaccine hesitancy, which has been reported in many countries, including Saudi Arabia [72,99,100]. Considering that COVID infection in patients with diabetes can result in debilitating and potentially life-threatening complications, it is important that vaccines be regularly advocated in individuals with diabetes mellitus to counter vaccine hesitancy and misconceptions due to conspiracy theories and other misinformation [64].

In this study, the status of full vaccination was associated with sex, age, and history of previous infection with COVID 19. Female patients had a lower rate of vaccination than male patients. Lower COVID-19 vaccination coverage in females compared to males is consistent with some other studies in the literature that showed a lower rate of COVID-19 vaccination [101] and a higher vaccine hesitancy among females [102]. A study from Maharashtra State, India, showed that only 84 women were vaccinated for every 100 men [101]. However, this is in contrast to the findings from the report on COVID-19 vaccination 
coverage among adults in the US that showed coverage with $\geq 1$ dose COVID-19 vaccine was higher among females compared to males (58.0\% versus 53.4\%, respectively) [103]. Moreover, the lower vaccine uptake among the elderly patients in this study is concerning, as it has the potential to increase the risk of serious COVID-19 infections. The coverage with $\geq 1$ dose COVID-19 vaccine is lower among the patients with age of $\geq 60$ compared to the younger age groups. Moreover, a considerable proportion (29.1\%) of elderly patients aged 80 and above was not vaccinated. This is in contrast to the situation in the US, in which elderly individuals and individuals aged $\geq 65$ years had a higher rate of vaccination than other age groups [103]. Therefore, it is important to explore the reasons for this lower rate of vaccination among patients with diabetes in older age groups and among females through qualitative inquiries and formulate interventions to reduce this hesitancy, alleviate barriers and improve confidence in vaccines. It is important to educate the public about recent changes and updates in vaccination requirements. For example, in this study, a higher percentage of individuals with prior infection were not vaccinated compared to those with no history of infection. In addition, only $14.6 \%$ of patients with prior infection are fully vaccinated (i.e., received 2 doses). In Saudi Arabia, the $\mathrm{MoH}$ protocol requires patients infected with COVID-19 to get vaccinated (1 dose) 6 months after the infection. However, this was updated in late July 2021, and it was indicated that the vaccine could be taken 10 days after the infection and that two doses are now required regardless of any prior COVID-19 infection [80]. In addition, mixing of vaccines was approved in early July 2021 (i.e., the 2nd dose can be from a different vaccine than the initial one, e.g., if the 1st dose is Oxford/AstraZeneca, then the 2nd dose can be Pfizer/BioNtech vaccine) [76]. Therefore, it is of great importance to keep the public aware of the updates and information given the rapid developments in the science and clinical evidence related to COVID-19 and its vaccines.

The study has several strengths. This is one of the first studies that explored the vaccination coverage status and infection rate among patients with diabetes. Another strength is using a diabetes registry with a large number of patients (more than 11,500 patients with diabetes) visiting four different chronic illness clinics in different areas of Riyadh, Saudi Arabia. In addition, to reduce any potential bias due to the sampling method, all the patients in the registry were included and their data were used for the next steps to determine the vaccination status and infection rate. Moreover, the vaccination status and infection history were retrieved from reliable sources (i.e., the official records) and not based on self-reporting or measuring the intentions, etc. However, the study had some limitations. The morbidity and mortality outcomes from COVID-19 infection among patients with diabetes, such as the rate of hospital admission and intensive care unit admission were not determined. However, this was out of the scope of our specific objective of this study. The study was conducted at a particular point of time in July 2021 and reflected the rate of vaccination at that time. In addition, it was conducted in one city of Saudi Arabia, and consequently, it might not be generalizable to all diabetes patients in the country. However, the study findings are robust and could provide further guidance to health authorities and healthcare professionals to accelerate vaccination coverage to the vulnerable groups of patients.

\section{Conclusions}

A considerable proportion of patients with type 2 diabetes had confirmed COVID-19 infection. Consequently, more education and awareness of patients with diabetes about the evidence-based and correct use of preventive measures to avoid COVID-19 infection are of great importance. The vaccination coverage rate was lower than anticipated in this group of patients based on the set targets of the national vaccination plan at the time of the study. Therefore, continued targeted efforts are needed to accelerate vaccination rates among patients with diabetes in general and particular subgroups, including elderly patients, females and patients with prior COVID-19 infection. More efforts are needed to increase confidence in vaccines, alleviate barriers, and address any hesitancy or misinformation 
among patients. Healthcare professionals and clinicians providing diabetes care could play a vital role and address the importance of vaccination with their patients as part of their therapeutic plan.

Author Contributions: Conceptualization, A.M.T., M.S.A. (Mohammad Saad AlEissa), A.F.A., I.H.A. and A.A.A.; methodology, A.M.T., S.M.A., M.N.A. and A.A.A.; software, M.S.A. (Mohammad Saad AlEissa), M.S.A. (Mohammed S. Almujil) and I.H.A.; validation, A.M.B.R., S.M.A., A.F.A., M.S.A. (Mohammed S. Almujil) and T.N.A.; formal analysis, A.A.A.; investigation, A.M.T., I.H.A., T.N.A. and M.N.A.; resources, A.M.B.R., M.S.A. (Mohammed S. Almujil), T.N.A. and M.N.A.; data curation, A.M.T., S.M.A., A.F.A. and T.N.A.; writing-original draft preparation, A.M.T., S.M.A. and A.A.A.; writing-review and editing, A.M.B.R., M.S.A. (Mohammad Saad AlEissa), A.F.A., M.S.A. (Mohammed S. Almujil), I.H.A., T.N.A., M.N.A. and A.A.A.; visualization, A.A.A., M.S.A. (Mohammed S. Almujil), T.N.A. and M.N.A.; supervision, A.M.T., A.F.A., M.N.A. and A.A.A.; project administration, A.M.B.R., A.F.A., M.S.A. (Mohammed S. Almujil) and T.N.A. All authors have read and agreed to the published version of the manuscript.

Funding: This research received no external funding.

Institutional Review Board Statement: The study was conducted in accordance with the Declaration of Helsinki, and approved by the Central Research Ethics Committee of the Armed Forces Medical Services Directorate (CREC-MSD), Prince Sultan Military Medical City, Riyadh, Saudi Arabia (Project approval No. 2021-46).

Informed Consent Statement: Consent was waived due to the retrospective nature of the study, and the data were anonymized before the analysis. In addition, it was not feasible to be taken from thousands of patients in the registry.

Data Availability Statement: The data will be available from the corresponding author upon reasonable request.

Acknowledgments: We would like to thank the following for their help in data collection: Raed Sarhan Alasmari, Abdulaziz Mohammed Alzahrani, Naif Mohammed Aladwani, Mohammed Saud AL-Otaibi, Helal Saud Alenazi, Waleed Nahar Alshammari, Abdulaziz Awadh Alanazi, Salman Abdullah Alamri, Mazen Hasan Abuella, Abdullah Mohammed Alanazi, Reuof Abdullah Bushnag, Jancy Thomson, Ahmed Mohammad Alazwari and Ghadeer Ali Albalawi. In addition, we would like to thank Abdulwahab M. Youzghadli for his help in data analysis and management.

Conflicts of Interest: The authors declare no conflict of interest.

\section{References}

1. Lu, R.; Zhao, X.; Li, J.; Niu, P.; Yang, B.; Wu, H.; Wang, W.; Song, H.; Huang, B.; Zhu, N.; et al. Genomic characterisation and epidemiology of 2019 novel coronavirus: Implications for virus origins and receptor binding. Lancet 2020, 395, 565-574. [CrossRef]

2. Vilella, A.; Trilla, A. The COVID-19 Pandemic-An Epidemiological Perspective. Curr. Allergy Asthma Rep. 2021, 21, 1-6. [CrossRef]

3. Das, K.; Pingali, M.S.; Paital, B.; Panda, F.; Pati, S.G.; Singh, A.; Varadwaj, P.K.; Samanta, S.K. A detailed review of the outbreak of COVID-19. Front. Biosci. -Landmark 2021, 26, 149-170. [CrossRef]

4. Karan, A.; Wadhera, R.K. Healthcare system stress due to COVID-19: Evading an evolving crisis. J. Hosp. Med. 2021, 16, 127. [CrossRef]

5. Trentini, F.; Marziano, V.; Guzzetta, G.; Tirani, M.; Cereda, D.; Poletti, P.; Piccarreta, R.; Barone, A.; Preziosi, G.; Arduini, F.; et al The pressure on healthcare system and intensive care utilization during the COVID-19 outbreak in the Lombardy region: A retrospective observational study on 43,538 hospitalized patients. Am. J. Epidemiol. 2021, 191, 137-146. [CrossRef]

6. Siow, W.T.; Liew, M.F.; Shrestha, B.R.; Muchtar, F.; See, K.C. Managing COVID-19 in resource-limited settings: Critical care considerations. Crit. Care 2020, 24, 167. [CrossRef]

7. Goschin, Z.; Dimian, G.C. Healthcare under pressure: Modelling COVID-19 fatalities with multiscale geographically weighted regressions. Kybernetes 2021. [CrossRef]

8. Hens, N.; Vranck, P.; Molenberghs, G. The COVID-19 epidemic, its mortality, and the role of non-pharmaceutical interventions. Eur. Heart J. Acute Cardiovasc. Care 2020, 9, 204-208. [CrossRef]

9. Locatelli, I.; Trächsel, B.; Rousson, V. Estimating the basic reproduction number for COVID-19 in Western Europe. PLoS ONE 2021, 16, e0248731. [CrossRef]

10. Hong, K.; Yum, S.J.; Kim, J.H.; Chun, B.C. Re-estimation of basic reproduction number of COVID-19 based on the epidemic curve by symptom onset date. Epidemiol. Infect. 2021, 149, e53. [CrossRef] 
11. Yu, C.-J.; Wang, Z.-X.; Xu, Y.; Hu, M.-X.; Chen, K.; Qin, G. Assessment of basic reproductive number for COVID-19 at global level: A meta-analysis. Medicine 2021, 100, e25837. [CrossRef] [PubMed]

12. Shil, P.; Atre, N.M.; Patil, A.A.; Tandale, B.V.; Abraham, P. District-wise estimation of Basic reproduction number (R0) for COVID-19 in India in the initial phase. Spat. Inf. Res. 2021, 30, 37-45. [CrossRef]

13. Rahman, B.; Sadraddin, E.; Porreca, A. The basic reproduction number of SARS-CoV-2 in Wuhan is about to die out, how about the rest of the world? Rev. Med. Virol. 2020, 30, e2111. [CrossRef]

14. Ives, A.R.; Bozzuto, C. Estimating and explaining the spread of COVID-19 at the county level in the USA. Commun. Biol. 2021, 4, 60. [CrossRef]

15. Beyrampour-Basmenj, H.; Milani, M.; Ebrahimi-Kalan, A.; Ben Taleb, Z.; Ward, K.; Dargahi Abbasabad, G.; Aliyari-serej, Z.; Ebrahimi Kalan, M. An Overview of the Epidemiologic, Diagnostic and Treatment Approaches of COVID-19: What do We Know. Public Health Rev. 2021, 42, 1604061. [CrossRef]

16. Worldometers. Coronavirus (COVID-19) Mortality Rate. Available online: https://www.worldometers.info/coronavirus/ coronavirus-death-rate/ (accessed on 13 November 2021).

17. Booth, A.; Reed, A.B.; Ponzo, S.; Yassaee, A.; Aral, M.; Plans, D.; Labrique, A.; Mohan, D. Population risk factors for severe disease and mortality in COVID-19: A global systematic review and meta-analysis. PLoS ONE 2021, 16, e0247461. [CrossRef]

18. Wolff, D.; Nee, S.; Hickey, N.S.; Marschollek, M. Risk factors for COVID-19 severity and fatality: A structured literature review. Infection 2021, 49, 15-28. [CrossRef]

19. Ahlström, B.; Frithiof, R.; Hultström, M.; Larsson, I.-M.; Strandberg, G.; Lipcsey, M. The swedish COVID-19 intensive care cohort: Risk factors of ICU admission and ICU mortality. Acta Anaesthesiol. Scand. 2021, 65, 525-533. [CrossRef]

20. Peña, J.E.-d.l.; Rascón-Pacheco, R.A.; Ascencio-Montiel, I.d.J.; González-Figueroa, E.; Fernández-Gárate, J.E.; Medina-Gómez, O.S.; Borja-Bustamante, P.; Santillán-Oropeza, J.A.; Borja-Aburto, V.H. Hypertension, Diabetes and Obesity, Major Risk Factors for Death in Patients with COVID-19 in Mexico. Arch. Med. Res. 2021, 52, 443-449. [CrossRef]

21. World Health Organization (WHO). WHO Coronavirus (COVID-19) Dashboard. Available online: https://covid19.who.int (accessed on 13 November 2021).

22. World Health Organization (WHO). Saudi Arabia: WHO Coronavirus Disease (COVID-19) Dashboard with Vaccination Data. Available online: https:/ / covid19.who.int/region/emro/country/sa (accessed on 13 November 2021).

23. Algaissi, A.A.; Alharbi, N.K.; Hassanain, M.; Hashem, A.M. Preparedness and response to COVID-19 in Saudi Arabia: Building on MERS experience. J. Infect. Public Health 2020, 13, 834-838. [CrossRef]

24. AlShoaibi, N.A.; Maghrabi, K.; Alanazi, H.; Harbi, M.A.; Alghamdi, S. Saudi Heart Rhythm Society Task Force on Management of Potential Arrhythmogenicity Associated with Pharmacotherapy for COVID-19. Ann. Saudi Med. 2020, 40, 365-372. [CrossRef]

25. Alsofyani, M.A.; Malaekah, H.M.; Bashawyah, A.; Bawazeer, M.; Akkour, K.; Alsalmi, S.; Alkhairy, A.; Dajim, N.B.; Khalifah, S.; Almalki, I.A. Safety measures for COVID-19: A review of surgical preparedness at four major medical centres in Saudi Arabia. Patient Saf. Surg. 2020, 14, 1-14. [CrossRef]

26. Alyamani, O.; Abushoshah, I.; Tawfeeq, N.A.; Al Dammas, F.; Algurashi, F.A. Considerations and recommendations for obstetric anesthesia care during COVID-19 pandemic-Saudi anesthesia society guidelines. Saudi J. Anaesth. 2020, 14, 359. [CrossRef]

27. Badreldin, H.A.; Raslan, S.; Almudaiheem, H.; Alomari, B.; Almowaina, S.; Joharji, H.; Alawagi, M.; Al-Jedai, A. Pharmacists roles and responsibilities during epidemics and pandemics in Saudi Arabia: An opinion paper from the Saudi Society of clinical pharmacy. Saudi Pharm. J. SPJ 2020, 28, 1030. [CrossRef]

28. Alkahtani, T.A.; Alakeel, A.; Alakeel, R.A.; Khorshid, F.A.; Alshammari, H.H.; Alguwaihes, A.M.; Almohideb, M.; Ali, E.M.; Bin-Jumah, M.; Abdel-Daim, M.M. The current reproduction number of COVID-19 in Saudi Arabia: Is the disease controlled? Environ. Sci. Pollut. Res. 2021, 28, 44812-44817. [CrossRef]

29. Cleveland Clinics. Diabetes: Types, Risk Factors, Symptoms, Tests, Treatments \& Prevention. Available online: https://my. clevelandclinic.org/health/diseases/7104-diabetes-mellitus-an-overview (accessed on 13 November 2021).

30. Erener, S. Diabetes, infection risk and COVID-19. Mol. Metab. 2020, 39, 101044. [CrossRef]

31. International Diabetes Federation (IDF) Diabetes Facts \& Figures. Available online: https://idf.org/aboutdiabetes/what-isdiabetes/facts-figures.html (accessed on 13 November 2021).

32. Carey, I.M.; Critchley, J.A.; DeWilde, S.; Harris, T.; Hosking, F.J.; Cook, D.G. Risk of infection in type 1 and type 2 diabetes compared with the general population: A matched cohort study. Diabetes Care 2018, 41, 513-521. [CrossRef]

33. Critchley, J.A.; Carey, I.M.; Harris, T.; DeWilde, S.; Hosking, F.J.; Cook, D.G. Glycemic control and risk of infections among people with type 1 or type 2 diabetes in a large primary care cohort study. Diabetes Care 2018, 41, 2127-2135. [CrossRef]

34. Norouzi, M.; Norouzi, S.; Ruggiero, A.; Khan, M.S.; Myers, S.; Kavanagh, K.; Vemuri, R. Type-2 Diabetes as a Risk Factor for Severe COVID-19 Infection. Microorganisms 2021, 9, 1211. [CrossRef]

35. Singh, A.K.; Gupta, R.; Ghosh, A.; Misra, A. Diabetes in COVID-19: Prevalence, pathophysiology, prognosis and practical considerations. Diabetes Metab. Syndr. Clin. Res. Rev. 2020, 14, 303-310. [CrossRef]

36. Wu, Z.-H.; Tang, Y.; Cheng, Q. Diabetes increases the mortality of patients with COVID-19: A meta-analysis. Acta Diabetol. 2021, 58, 139-144. [CrossRef]

37. Corona, G.; Pizzocaro, A.; Vena, W.; Rastrelli, G.; Semeraro, F.; Isidori, A.M.; Pivonello, R.; Salonia, A.; Sforza, A.; Maggi, M. Diabetes is most important cause for mortality in COVID-19 hospitalized patients: Systematic review and meta-analysis. Rev. Endocr. Metab. Disord. 2021, 22, 275-296. [CrossRef] 
38. Palaiodimos, L.; Chamorro-Pareja, N.; Karamanis, D.; Li, W.; Zavras, P.D.; Chang, K.M.; Mathias, P.; Kokkinidis, D.G. Diabetes is associated with increased risk for in-hospital mortality in patients with COVID-19: A systematic review and meta-analysis comprising 18,506 patients. Hormones 2021, 20, 305-314. [CrossRef]

39. Varikasuvu, S.R.; Dutt, N.; Thangappazham, B.; Varshney, S. Diabetes and COVID-19: A pooled analysis related to disease severity and mortality. Prim. Care Diabetes 2021, 15, 24-27. [CrossRef]

40. Alguwaihes, A.M.; Al-Sofiani, M.E.; Megdad, M.; Albader, S.S.; Alsari, M.H.; Alelayan, A.; Alzahrani, S.H.; Sabico, S.; Al-Daghri, N.M.; Jammah, A.A. Diabetes and COVID-19 among hospitalized patients in Saudi Arabia: A single-centre retrospective study. Cardiovasc. Diabetol. 2020, 19, 205. [CrossRef]

41. Pal, R.; Bhadada, S.K.; Misra, A. COVID-19 vaccination in patients with diabetes mellitus: Current concepts, uncertainties and challenges. Diabetes Metab. Syndr. Clin. Res. Rev. 2021, 15, 505-508. [CrossRef]

42. Robert, A.A.; Al Saeed, A.; Al Dawish, M.A. COVID-19 among people with diabetes mellitus in Saudi Arabia: Current situation and new perspectives. Diabetes Metab. Syndr. Clin. Res. Rev. 2021, 15, 102231. [CrossRef]

43. Frielitz, F.-S.; Wagner, I.V.; Schewe, D.M.; Bothe, K. COVID-19: Would compulsory vaccination be legally possible? Dtsch. Med. Wochenschr. (1946) 2021, 146, 206-208.

44. Rawat, K.; Kumari, P.; Saha, L. COVID-19 vaccine: A recent update in pipeline vaccines, their design and development strategies Eur. J. Pharmacol. 2020, 892, 173751. [CrossRef]

45. Christie, A.; Brooks, J.T.; Hicks, L.A.; Sauber-Schatz, E.K.; Yoder, J.S.; Honein, M.A.; COVID, C.; Team, R. Guidance for implementing COVID-19 prevention strategies in the context of varying community transmission levels and vaccination coverage. Morb. Mortal. Wkly. Rep. 2021, 70, 1044. [CrossRef]

46. Ndwandwe, D.; Wiysonge, C.S. COVID-19 vaccines. Curr. Opin. Immunol. 2021, 71, 111-116. [CrossRef]

47. Moline, H.L.; Whitaker, M.; Deng, L.; Rhodes, J.C.; Milucky, J.; Pham, H.; Patel, K.; Anglin, O.; Reingold, A.; Chai, S.J.; et al. Effectiveness of COVID-19 Vaccines in Preventing Hospitalization Among Adults Aged $\geq 65$ Years-COVID-NET, 13 States, February-April 2021. MMWR Morb. Mortal. Wkly. Rep. 2021, 70, 1088-1093. [CrossRef]

48. Tenforde, M.W.; Self, W.H.; Naioti, E.A.; Ginde, A.A.; Douin, D.J.; Olson, S.M.; Talbot, H.K.; Casey, J.D.; Mohr, N.M.; Zepeski, A.; et al. Sustained Effectiveness of Pfizer-BioNTech and Moderna Vaccines Against COVID-19 Associated Hospitalizations Among Adults-United States, March-July 2021. MMWR Morb. Mortal. Wkly. Rep. 2021, 70, 1156-1162. [CrossRef]

49. Meo, S.A.; Bukhari, I.A.; Akram, J.; Meo, A.S.; Klonoff, D.C. COVID-19 vaccines: Comparison of biological, pharmacological characteristics and adverse effects of Pfizer/BioNTech and Moderna Vaccines. Eur. Rev. Med. Pharmacol. Sci. 2021, 25, 1663-1669. [CrossRef]

50. Patel, N.; Bouchard, J.; Oliver, M.B.; Badowski, M.E.; Carreno, J.J. Early clinical trial data and real-world assessment of COVID-19 vaccines: Insights from the Society of Infectious Diseases Pharmacists. Pharmacotherapy 2021, 41, 837-850. [CrossRef]

51. Azar, W.S.; Njeim, R.; Fares, A.H.; Azar, N.S.; Azar, S.T.; El Sayed, M.; Eid, A.A. COVID-19 and diabetes mellitus: How one pandemic worsens the other. Rev. Endocr. Metab. Disord. 2020, 21, 451-463. [CrossRef] [PubMed]

52. Chee, Y.J.; Tan, S.K.; Yeoh, E. Dissecting the interaction between COVID-19 and diabetes mellitus. J. Diabetes Investig. 2020, 11, 1104-1114. [CrossRef]

53. Soiza, R.L.; Scicluna, C.; Thomson, E.C. Efficacy and safety of COVID-19 vaccines in older people. Age Ageing 2021, 50, 279-283 [CrossRef]

54. Saudi Press Agency. SFDA Approves Registration of Pfizer-BioNTech COVID-19 Vaccine. Available online: https://www.spa. gov.sa/viewfullstory.php?lang=en\&newsid=2166947 (accessed on 13 November 2021).

55. Saudi Press Agency. SFDA Approves Importing, Using Oxford-AstraZeneca COVID-19 Vaccine. Available online: https: / / www.spa.gov.sa/viewfullstory.php?lang=en\&newsid=2192728 (accessed on 13 November 2021).

56. Saudi Press Agency. SFDA Approves Registration of Moderna COVID-19 Vaccine. Available online: https://www.spa.gov.sa/ viewfullstory.php?lang=en\&newsid=2256283 (accessed on 13 November 2021).

57. Assiri, A.; Al-Tawfiq, J.A.; Alkhalifa, M.; Al Duhailan, H.; Al Qahtani, S.; Dawas, R.A.; El Seoudi, A.A.; Alomran, N.; Omar, O.A.; Alotaibi, N. Launching COVID-19 vaccination in Saudi Arabia: Lessons learned, and the way forward. Travel Med. Infect. Dis. 2021, 43, 102119. [CrossRef]

58. Ministry of Health. COVID-19 \& Vaccines FAQS. Available online: https://www.moh.gov.sa/en/Ministry/HotTopics/Pages/ COVID-19-Vaccine.aspx (accessed on 5 November 2021).

59. Minsitry of Health SA. Launching the COVID-19 Vaccination Program in Saudi Arabia. Available online: https://www.moh.gov. sa/Ministry/MediaCenter/News/Pages/News-2020-12-17-007.aspx (accessed on 13 November 2021).

60. Saudi Press Agency. Launching the COVID-19 Vaccination Program and the Stages of the Program. Available online: https: / / www.spa.gov.sa/2168181 (accessed on 13 November 2021).

61. Unified National Platform. Registering for COVID-19 Vaccination and the Stages of the National Vaccination Program. Available online: https:/ / www.my.gov.sa/wps/portal/snp/servicesDirectory/servicedetails/s9123 (accessed on 13 November 2021).

62. Ministry of Health SA. Announcement of the Second Stage of the Vaccine Program. Available online: https://twitter.com/ SaudiMOH/status/1362297708850143233?ref_src=twsrc\%5Etfw (accessed on 13 November 2021).

63. Ministry of Health SA. Number of COVID-19 Vaccination Centers in Saudi Arabia. Available online: https://twitter.com/ SaudiMOH/status/1455569601941671937/photo/1 (accessed on 13 November 2021). 
64. Romer, D.; Jamieson, K.H. Conspiracy theories as barriers to controlling the spread of COVID-19 in the US. Soc. Sci. Med. 2020, 263, 113356. [CrossRef]

65. Douglas, K.M. COVID-19 conspiracy theories. Group Processes Intergroup Relat. 2021, 24, 270-275. [CrossRef]

66. Khairat, S.; Zou, B.; Adler-Milstein, J. Factors and Reasons Associated with Low COVID-19 Vaccine Uptake among Highly Hesitant Communities in the US. Am. J. Infect. Control. 2022, in press. [CrossRef] [PubMed]

67. King, W.C.; Rubinstein, M.; Reinhart, A.; Mejia, R. Time trends, factors associated with, and reasons for COVID-19 vaccine hesitancy: A massive online survey of US adults from January-May 2021. PLoS ONE 2021, 16, e0260731. [CrossRef] [PubMed]

68. Alshehry, A.S.; Cruz, J.P.; Alquwez, N.; Alsharari, A.F.; Tork, H.M.; Almazan, J.U.; Alshammari, F.; Alabdulaziz, H.; Alsolami, F.; Tumala, R.B. Predictors of nursing students' intention to receive COVID-19 vaccination: A multi-university study in Saudi Arabia. J. Adv. Nurs. 2022, 78, 446-457. [CrossRef]

69. Loomba, S.; de Figueiredo, A.; Piatek, S.J.; de Graaf, K.; Larson, H.J. Measuring the impact of COVID-19 vaccine misinformation on vaccination intent in the UK and USA. Nat. Hum. Behav. 2021, 5, 337-348. [CrossRef] [PubMed]

70. Ministry of Health SA. Half of the Population Received Two Doses of the Vaccine. Available online: https://www.aleqt.com/20 21/09/17/article_2173101.html (accessed on 13 November 2021).

71. Noushad, M.; Nassani, M.Z.; Koppolu, P.; Alsalhani, A.B.; Samran, A.; Alqerban, A.; Abusalim, G.S.; Barakat, A.; Alshalhoub, M.B.; Rastam, S. Predictors of COVID-19 vaccine intention among the saudi arabian population: A cross-sectional survey. Vaccines 2021, 9, 892. [CrossRef]

72. Aldossari, K.K.; Alharbi, M.B.; Alkahtani, S.M.; Alrowaily, T.Z.; Alshaikhi, A.M.; Twair, A.A. COVID-19 vaccine hesitancy among patients with diabetes in Saudi Arabia. Diabetes Metab. Syndr. Clin. Res. Rev. 2021, 15, 102271. [CrossRef]

73. Al-Mansour, K.; Alyahya, S.; AbuGazalah, F.; Alabdulkareem, K. Factors Affecting COVID-19 Vaccination among the General Population in Saudi Arabia. Healthcare 2021, 9, 1218. [CrossRef]

74. Ministry of Health SA. Announcement of Starting Administering the 2nd Dose for Persons of 60 and Above. Available online: https://www.moh.gov.sa/Ministry/MediaCenter/News/Pages/News-2021-05-28-001.aspx (accessed on 13 November 2021).

75. Ministry of Health SA. Announcement of Starting Administering the 2nd Dose for Persons of 50 Years and Above. Available online: https:/ / www.alwatan.com.sa/article/1079508 (accessed on 13 November 2021).

76. Ministry of Health SA. Approval of Mixing Vaccines in Saudi Arabia. Available online: https://www.moh.gov.sa/Ministry/ MediaCenter/News/Pages/News-2021-06-23-007.aspx (accessed on 13 November 2021).

77. Saudi Press Agency. Announcement of Approval of Vaccines for the Age Group 12-18 with Pfizer/BioNteck Vaccine. Available online: https:/ / www.spa.gov.sa/2246602 (accessed on 13 November 2021).

78. Ministry of Health SA. Announcement of Starting Administering the 2nd Dose for Persons of 40 Years and Above. Available online: https:/ / www.moh.gov.sa/Ministry/MediaCenter/News/Pages/News-2021-07-05-008.aspx (accessed on 13 November 2021).

79. Ministry of Health SA. Announcement of Administering the 2nd Dose for All Eligible Persons from All Age Groups. Available online: https:/ / twitter.com/SaudiMOH/status/1414201732285018115 (accessed on 13 November 2021).

80. Saudi Press Agency. Approval of Taking the COVID-19 Vaccines after 10 Days from Recovery of the Infection. Available online: https: / / www.spa.gov.sa/2266653 (accessed on 13 November 2021).

81. Saudi Food and Drug Authority. Approval of Pfizer/BioNteck Vaccine for the Age Group 5-11. Available online: https: / / sfda.gov.sa/ar/news/ 85832 (accessed on 13 November 2021).

82. Al-Amer, R.; Maneze, D.; Everett, B.; Montayre, J.; Villarosa, A.R.; Dwekat, E.; Salamonson, Y. COVID-19 vaccination intention in the first year of the pandemic: A systematic review. J. Clin. Nurs. 2021, 31, 62-86. [CrossRef]

83. Al-Metwali, B.Z.; Al-Jumaili, A.A.; Al-Alag, Z.A.; Sorofman, B. Exploring the acceptance of COVID-19 vaccine among healthcare workers and general population using health belief model. J. Eval. Clin. Pract. 2021, 27, 1112-1122. [CrossRef]

84. Al-Mohaithef, M.; Padhi, B.K. Determinants of COVID-19 Vaccine Acceptance in Saudi Arabia: A Web-Based National Survey. J. Multidiscip. Healthc. 2020, 13, 1657-1663. [CrossRef] [PubMed]

85. Al-Mohaithef, M.; Padhi, B.K.; Ennaceur, S. Socio-Demographics Correlate of COVID-19 Vaccine Hesitancy During the Second Wave of COVID-19 Pandemic: A Cross-Sectional Web-Based Survey in Saudi Arabia. Front. Public Health 2021, 9, 698106. [CrossRef]

86. Ashok, N.; Krishnamurthy, K.; Singh, K.; Rahman, S.; Majumder, M.A.A. High COVID-19 Vaccine Hesitancy Among Healthcare Workers: Should Such a Trend Require Closer Attention by Policymakers? Cureus 2021, 13, e17990. [CrossRef] [PubMed]

87. Gagneux-Brunon, A.; Detoc, M.; Bruel, S.; Tardy, B.; Rozaire, O.; Frappe, P.; Botelho-Nevers, E. Intention to get vaccinations against COVID-19 in French healthcare workers during the first pandemic wave: A cross-sectional survey. J. Hosp. Infect. 2021, 108, 168-173. [CrossRef] [PubMed]

88. Konopińska, J.; Obuchowska, I.; Lisowski, Ł.; Dub, N.; Kozera, M.; Rękas, M. Intention to Get COVID-19 Vaccinations among Ophthalmology Residents in Poland: A Cross-Sectional Survey. Vaccines 2021, 9, 371. [CrossRef] [PubMed]

89. Magadmi, R.M.; Kamel, F.O. Beliefs and barriers associated with COVID-19 vaccination among the general population in Saudi Arabia. BMC Public Health 2021, 21, 1438. [CrossRef] [PubMed]

90. Malik, A.A.; McFadden, S.M.; Elharake, J.; Omer, S.B. Determinants of COVID-19 vaccine acceptance in the US. EClinicalMedicine 2020, 26, 100495. [CrossRef] 
91. Pacella-LaBarbara, M.L.; Park, Y.L.; Patterson, P.D.; Doshi, A.; Guyette, M.K.; Wong, A.H.; Chang, B.P.; Suffoletto, B.P. COVID-19 Vaccine Uptake and Intent Among Emergency Healthcare Workers: A Cross-Sectional Survey. J. Occup Environ. Med. 2021, $63,852-856$. [CrossRef]

92. Paul, E.; Steptoe, A.; Fancourt, D. Attitudes towards vaccines and intention to vaccinate against COVID-19: Implications for public health communications. Lancet Reg. Health-Eur. 2021, 1, 100012. [CrossRef]

93. Ruiz, J.B.; Bell, R.A. Predictors of intention to vaccinate against COVID-19: Results of a nationwide survey. Vaccine 2021, 39, $1080-1086$. [CrossRef]

94. Sherman, S.M.; Smith, L.E.; Sim, J.; Amlôt, R.; Cutts, M.; Dasch, H.; Rubin, G.J.; Sevdalis, N. COVID-19 vaccination intention in the UK: Results from the COVID-19 vaccination acceptability study (CoVAccS), a nationally representative cross-sectional survey. Hum. Vaccines Immunother. 2021, 17, 1612-1621. [CrossRef] [PubMed]

95. Batra, U.; Nathany, S.; Bansal, N.; Sharma, M. COVID-19 vaccination status in Indian patients with cancer: An observational study. Cancer Res. Stat. Treat. 2021, 4, 219-223. [CrossRef]

96. Lim, S.; Bae, J.H.; Kwon, H.-S.; Nauck, M.A. COVID-19 and diabetes mellitus: From pathophysiology to clinical management. Nat. Rev. Endocrinol. 2021, 17, 11-30. [CrossRef] [PubMed]

97. Lima-Martínez, M.M.; Boada, C.C.; Madera-Silva, M.D.; Marín, W.; Contreras, M. COVID-19 y diabetes mellitus: Una relación bidireccional. Clin. E Investig. En Arterioscler. 2021, 33, 151. [CrossRef]

98. Zhou, Y.; Chi, J.; Lv, W.; Wang, Y. Obesity and diabetes as high-risk factors for severe coronavirus disease 2019 (COVID-19). Diabetes/Metab. Res. Rev. 2021, 37, e3377. [CrossRef]

99. Khubchandani, J.; Sharma, S.; Price, J.H.; Wiblishauser, M.J.; Sharma, M.; Webb, F.J. COVID-19 vaccination hesitancy in the United States: A rapid national assessment. J. Community Health 2021, 46, 270-277. [CrossRef]

100. Solís Arce, J.S.; Warren, S.S.; Meriggi, N.F.; Scacco, A.; McMurry, N.; Voors, M.; Syunyaev, G.; Malik, A.A.; Aboutajdine, S.; Adeojo, O.; et al. COVID-19 vaccine acceptance and hesitancy in low- and middle-income countries. Nat. Med. 2021, 27, 1385-1394. [CrossRef]

101. Potdar, M.; Potdar, S.; Potdar, M. A study of gender disparities towards COVID-19 vaccination drive in Maharashtra State, India. Diabetes Metab. Syndr. Clin. Res. Rev. 2021, 15, 102297. [CrossRef]

102. Green, M.S.; Abdullah, R.; Vered, S.; Nitzan, D. A study of ethnic, gender and educational differences in attitudes toward COVID-19 vaccines in Israel-implications for vaccination implementation policies. Isr. J. Health Policy Res. 2021, 10, 26. [CrossRef]

103. Diesel, J.; Sterrett, N.; Dasgupta, S.; Kriss, J.L.; Barry, V.; Vanden Esschert, K.; Whiteman, A.; Cadwell, B.L.; Weller, D.; Qualters, J.R.; et al. COVID-19 Vaccination Coverage Among Adults-United States, December 14, 2020-May 22, 2021. MMWR Morb. Mortal. Wkly. Rep. 2021, 70, 922-927. [CrossRef] 